\title{
CARDIOPROTECTIVE EFFECT OF CILOSTAZOL VERSUS CLOPIDOGREL IN EXPERIMENTALLYINDUCED MYOCARDIAL INFARCTION IN MALE ALBINO RATS
}

\author{
BY \\ El Sayed M. Kamel; Laila A. Mahgoub; Monira I. Khattab and Doaa M. Abdullah \\ FROM \\ Department of Clinical Pharmacology, Faculty of Medicine Zagazig University
}

\begin{abstract}
Antiplatelet agents remain the cornerstone treatment in patients with ischemic heart diseases, as they decrease the mortality as well as the recurrence of cardiovascular complications. This study aimed to assess and compare the possible cardioprotective effect of cilostazol, clopidogrel and their combination in experimentally induced myocardial ischemia/reperfusion $(\mathrm{MI} / \mathrm{R})$ in rats.In this study ninety-six rats were divided into six equal groups (each of 16 rats): group 1, control normal received the vehicle; group 2, sham-operated and received the vehicle; group 3 (MI/R-treated) where myocardial infarction was induced by left coronary artery ligation (LCAL) for $30 \mathrm{~min}$, followed by 2 h. reperfusion; group 4 received cilostazol (20 mg/kg, p.o.); group 5 received clopidogrel (30 mg/kg, p.o.); group 6 received combination of both drugs in the same doses. In all treated groups (groups $4,5 \& 6$ ), drugs were administered for 3days, then they were exposed to MI/R. Results of the present study revealed that MI/R injury induced a significant decrease in mean arterial blood pressure (MABP), increase in heart rate (HR), elevation in T-wave voltage along with increased infarct size, plasma cardiac troponin I (cTnI) level and tumor necrosis factor alpha (TNF- $\alpha$ ) and heart content ofmalondialdehyde (MDA), consequently with reduction in heart tissue glutathione peroxidase (GPx) activity. Cilostazol, clopidogrel or their coadministration exerted cardioprotective effect manifested by significant reductions in the $\mathrm{T}$-wave voltage, infarct size and cTnI level via enhancement of antioxidant capacity and prevention of inflammatory and oxidative stress cascades. Additionally, cilostazol increased the HDL and decreased the LDL levels. It could be concluded that cilostazol is an effective cardioprotective agentin treatment of myocardial infarction particularly when used as an adjuvant to clopidogrel.
\end{abstract}


Key words: Antiplatelet; Cilostazol; Clopidogrel; MI/R; GPx; MDA; TNF- $\alpha$; cTnI.

\section{Introduction}

Acute myocardial infarction (AMI) is a clinical condition caused by necrosis of myocardial tissue due to ischemia, usually by occlusion of a coronary artery with a thrombus (Amsterdam et al., 2014). It is considered a global disease burden and a major cause of morbidity and mortality worldwide. Its prevalence is continuously increasing particularly in advanced countries despite the considerable progress in its management (Moran et al., 2014).

Reducing myocardial infarct size is the primary goal in patients with AMI and early reperfusion of an occluded coronary artery is a well-known and effective strategy to reduce ischemia-induced myocardial damage (Cannon and Braunwald, 2012). Moreover, dual antiplatelet therapy (DAPT) by aspirin and clopidogrel is the cornerstone medical treatment as they decrease the mortality as well as the recurrence of cardiovascular events (Acharji et al., 2013).

Many previous studies have implicated an essential role for reperfusion, in order to salvage tissue from inevitable necrosis, however it is considered a double-edged sword, as such; restoration of blood flow can provoke further myocardial damage known as ischemia reperfusion (I/R) injury. Jennings et al. (1960)documented a landmark study showing that reperfusion in AMI accelerates further myocardial injury. Hence, mortality is not only associated with deficient coronary circulation but rather with damage consequent to $I / R$ (Jang et al., 2010).

The pathogenesis of I/R-induced myocardial injury involves various factors that can provoke further myoca-rdial damage including inflammatory and oxidative stress, intracellular Ca overload, apoptotic and necrotic myocytes death (Rohilla et al., 2012).

Clopidogrel is an oral antiplatelet agent that inhibits the $\mathrm{P}_{2} \mathrm{Y}_{12}$ ADP receptor subtype on platelets and isused as an adjunct to aspirin in acute coronary syndrome and percutaneous coronary intervention patients (Tantry et al., 2013). However, complicated thrombotic events still occur after routine DAPT with aspirin and clopidogrel(Sakurai et al., 2013). 
Cilostazol is a phosphodiesterase-III inhibitor that has an anti-platelet and vasodilator activity as ascribed to the increased levels of cyclic AMP in platelets and vascular smooth muscle cells (Rondina and Weyrich, 2013). It may attenuate aspirin and clopidogrel resistance because its antiplatelet mechanism is quite different (Kim et al., 2011).It is used for the treatment of peripheral vascular diseases such as intermittent claudication and for secondary prevention of brain infarction (Shinohara et al., 2010; Rondina and Weyrich, 2013). However, because peripheral arterial disease is frequently associated with coronary artery disease, it is important to investigate whether cilostazol is also cardio protective. Moreover, little information is available to determine the cardio protective effect of adjunctive cilostazol compared with clopidogrel alone in those patients (Tanaka et al., 2014).

Although the accumulated evidences implicate cilostazol in ameliorating oxidative stress as well as inflammatory mediators in various studies, the possibility that cilostazol may guard against myocardial I/R injury has not yet been fully explored. Therefore, this study aimed to assess and compare the possible cardioprotective effect of cilostazol, clopidogrel and their combinations on experimentally induced myocardial ischemia reperfusion injury in rats.

\section{Materials and methods}

\section{Animals}

Ninety-six adult male albino rats (200-220 g) were used in the current study. Animals were kept at a constant temperature $\left(23 \pm 2{ }^{\circ} \mathrm{C}\right)$, humidity $(60 \pm 10 \%)$, and a light/dark (12/12 h) cycle. Food and water were available ad libitum. Experimental design and animal handling were approved by the local authorities at the Faculty of medicine, Zagazig University, Egypt (Ethical Committee for Animal Handling at Zagazig University).

\section{Dugs and Chemicals}

Cilostazolpowder was obtained from Otsuka Co., Egypt, suspended in 2\%. arabic gum solution and orally administered at a dose of $20 \mathrm{mg} / \mathrm{kg}$ in a volume of $5 \mathrm{ml} / \mathrm{kg}$ (Manickavasagam et al., 2007; Ito et al., 2010).Clopidogrel powder was purchased from Sigma Co., Egypt, suspended in $2 \%$ arabic gum solution and orally administered at a dose of $30 \mathrm{mg} / \mathrm{kg}$ in a volume of $5 \mathrm{ml} / \mathrm{kg}$ (Ito et al., 2010; Birnbaum, 2014). Ethylcarbamate(urethane) was obtained from Prolabo, Paris, given i.p. at a dose of $1.5 \mathrm{gm}$ $/ \mathrm{kg}$ and used for anaesthesiaof rats (Gosh, 1971). All other chemicals used were of the highest analytical grades available commercially.

\section{Experimental design}

Animals were randomly divided into six equal groups (16 rats each) as follows:

Group 1: Control normal received 2\% arabic gum solution orally.

Group 2: Sham-operated received 2\% arabic gum solution orally. 
Group 3: Rats were subjected to 30 min left anterior descending coronary artery ligation (LCAL), followed by $2 \mathrm{~h}$ reperfusion (Humphreys et al., 1999) to serve as MI/R group.

Group 4: Rats received cilostazolat a dose of $20 \mathrm{mg} / \mathrm{kg}$ orally.

Group 5: Rats received clopidogrelat a dose of $30 \mathrm{mg} / \mathrm{kgorally}$.

Group 6: Rats received combination of both drugs in the same doses orally.

In all treated groups, drugs were administered for 3days before being subjected to MI/R. 


\section{Measurement of hemodynamic parameters}

The $\mathrm{T}$ wave voltages mean arterial blood pressure (MABP) and heart rate (HR) were recorded by the use of Power Lab data acquisition and analysis system (AD Instruments, Australia) and the data were automatically analyzed and stored in a computer. The amount of elevated $\mathrm{T}$ wave (in $\mathrm{mV}$ ) in different groups was recruited as an index of myocardial ischemia and was statistically compared.

\section{Determination of myocardial infarct size}

At the end of $2 \mathrm{~h}$ reperfusion, eight hearts from each group were removed. The entire ventricles were separated from the heart then sliced into $2 \mathrm{~mm}$ transverse sections thickness and incubated with $1 \%$ triphenyltetrazolium chloride (TTC) stain at $37{ }^{\circ} \mathrm{C}$ (prepared as $10 \mathrm{mg} / \mathrm{mL}$ in a $\mathrm{pH} 7.4$ phosphate buffer) for $20 \mathrm{~min}$ to visualize the infarct area as described by Nachlas and Schnitka (1963). Infarcted area was expressed as a percentage of total sliced areas (Frantz et al., 2005).

\section{Blood and tissue collection}

At the end of the experiment, $2 \mathrm{ml}$ blood sample were collected from carotid artery via rat arterial polyethylene cannula in heparinized tubes. The samples were centrifuged and plasma was used for cTnI, TNF- $\alpha$ and lipoproteins assessment. Hearts of the other eight rats of each group were collected, homogenized in the appropriate buffer, the homogenate was centrifuged, and the supernatant was used according to the manufacturer's instructions for estimation of GPx activity and MDA content of heart.

The cTnI plasma level was measured with a commercial ELISA kits (CUSABIO, China) following the manufacturer's instructions.

Plasma levels of TNF- $\alpha$ level was measured with a commercial ELISA kits (R\&D Systems, USA) following the instructions of the manufacturer. Lipid peroxidation was measured by determination of the MDA content by the method of Utley et al. (1967) using colorimetric assay kits (Biodiagnostic, Egypt) according to the manufacturer's instructions.

The GPx activity was assessed usingBiodiagnostic kits (Egypt) by the UV method of Paglia and Valentine (1967) and according to the manufacturer's instructions.

Total cholesterol (TC) and high-density lipoproteins (HDL-C) were estimated in plasma enzymatically using Spinreact diagnostic kits (Spain) by Naito's method (1984) according to the manufacturer's instructions.

The LDL cholesterol (LDL-C) was determined by enzymatic colorimetric method using Spinreact diagnostic kits (Spain) by the method of Okada et al. (1998) and according to the manufacturer's instructions. 


\section{Statistical analysis of data}

Data were collected, tabulated and expressed as means \pm SEM. Statistical comparison between different groups was done using one-way analysis of variance (ANOVA), followed by Post-Hoc (least significant difference "LSD") tests using SPSS 20 evaluation version computer program (SPSS Inc., Chicago, IL). Statistical significance was established at $\mathrm{P} \leq 0.05$.

\section{Results}

\section{Effects on the $T$ wave voltage}

As shown in Fig. 1 and photo 1, LCAL significantly $(\mathrm{p} \leq 0.05)$ increased the $\mathrm{T}$ wave voltage as compared to the control normal group. Meanwhile, administration of cilostazol $(20 \mathrm{mg} / \mathrm{kg})$, clopidogrel $(30 \mathrm{mg} / \mathrm{kg})$ and their combination caused significant $(\mathrm{p} \leq 0.05)$ reduction of $\mathrm{T}$ wave voltage when compared with that of $\mathrm{MI} / \mathrm{R}$ group.

Fig. (1): Effect of pretreatment with cilostazol (20 mg/kg, po), clopidogrel (30 $\mathrm{mg} / \mathrm{kg}, \mathrm{po}$ ) or their combination on the T-wave voltage in experimentally-induced myocardial ischemia/reperfusion (MI/R) in male albino rats.

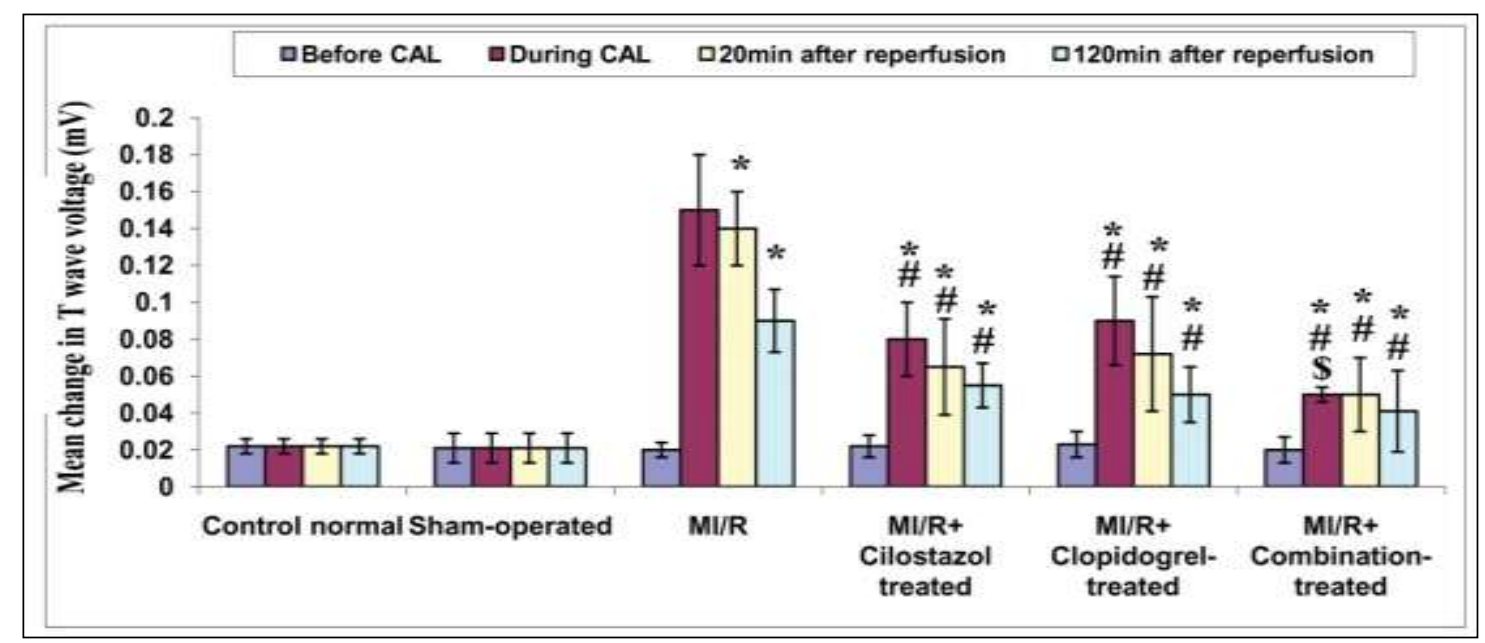

Data represent the means of eight experiments \pm SEM.

* significantly different compared with normal; \# significantly different compared with MI/R; \$ significantly different compared with cilostazol or clopidogrel using one way ANOVA, followed by LSD test for multiple comparison between groups at $\mathrm{P} \leq 0.05$. 


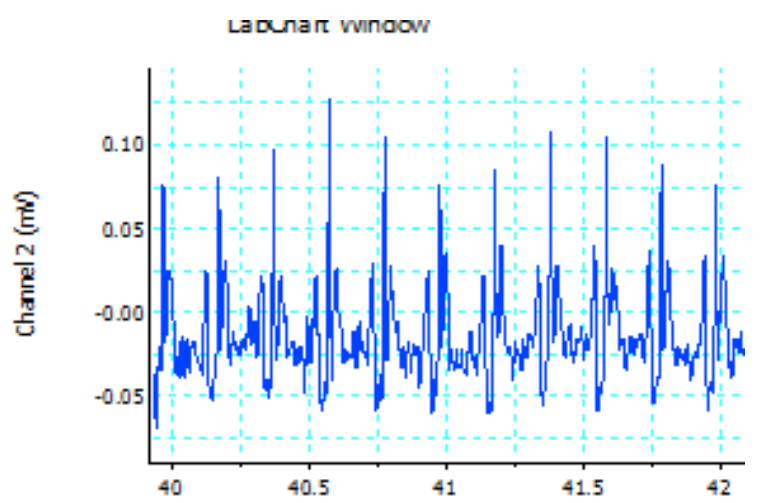

Control normal group

LabChart Window

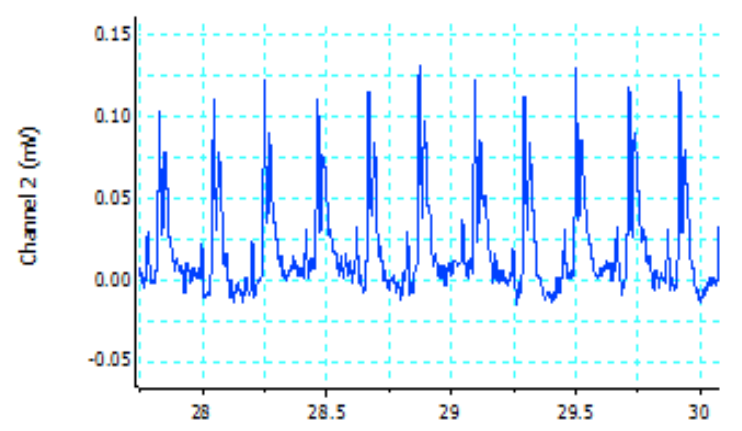

Clopidogrel-treated group during LCAL

LabChart Window

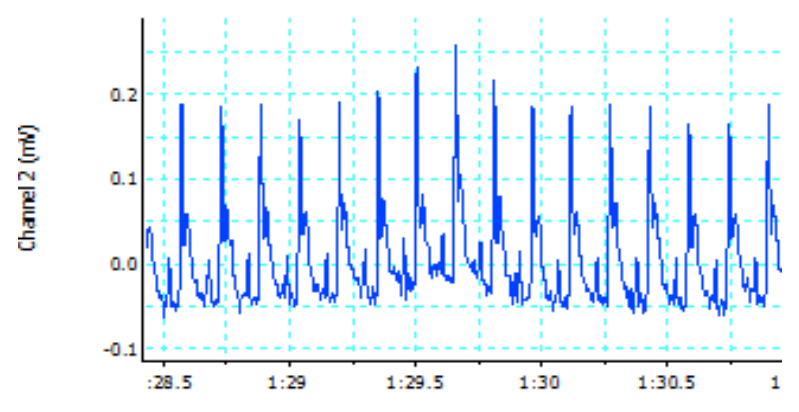

Combination-treated group during LCAL LabChart Window

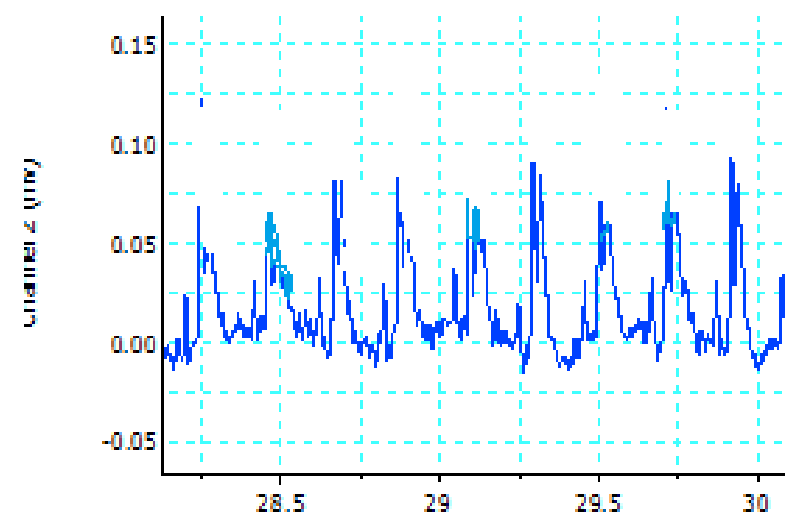

Clopidogrel-treated group at the end of reperfusion

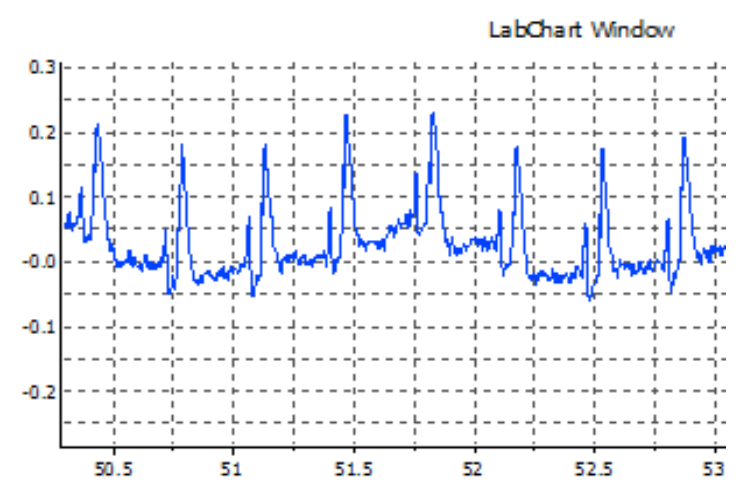

MI/R group during LCAL

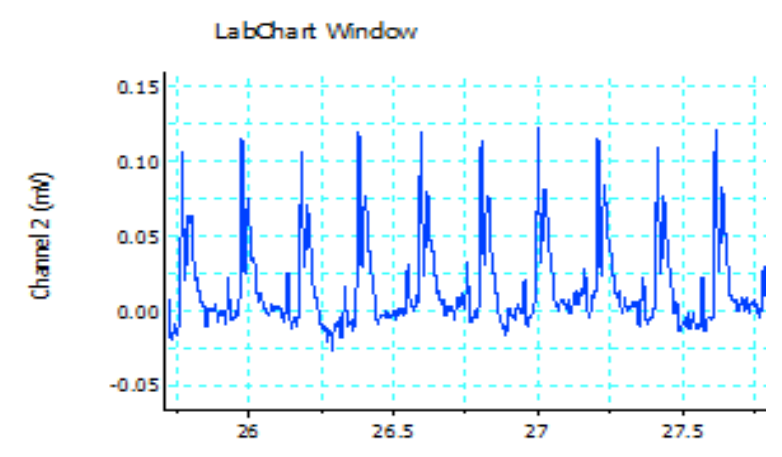

Cilostazol -treated group during LCAL

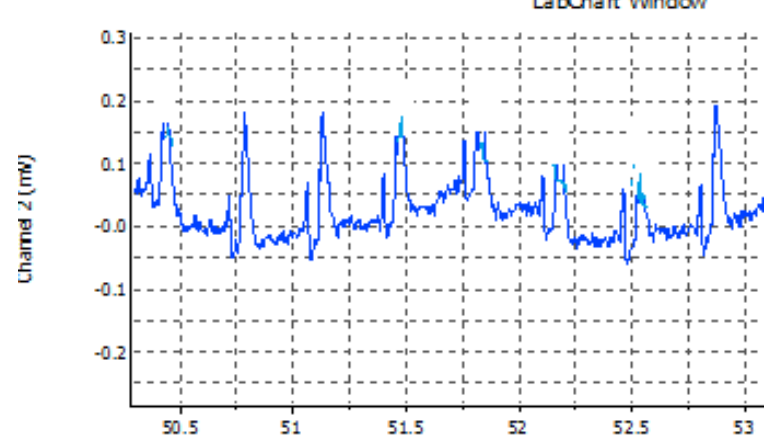

MI/R group at the end of reperfusion

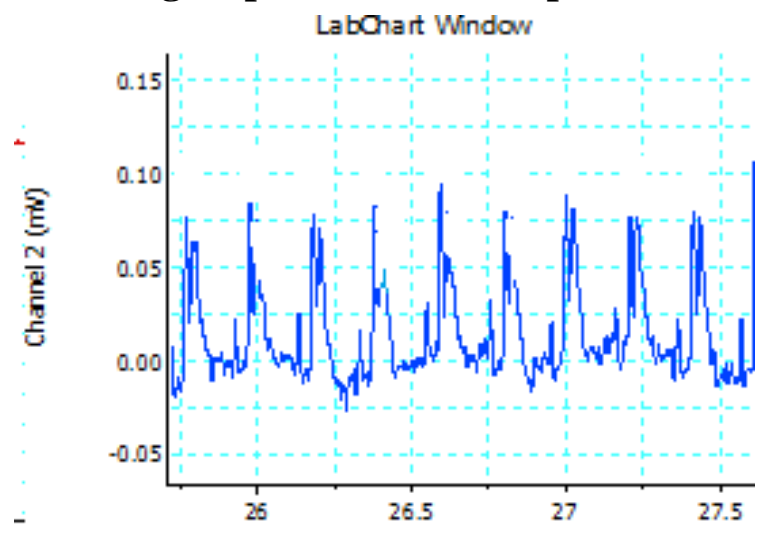

Cilostazol-treated group at the end of reperfusion 


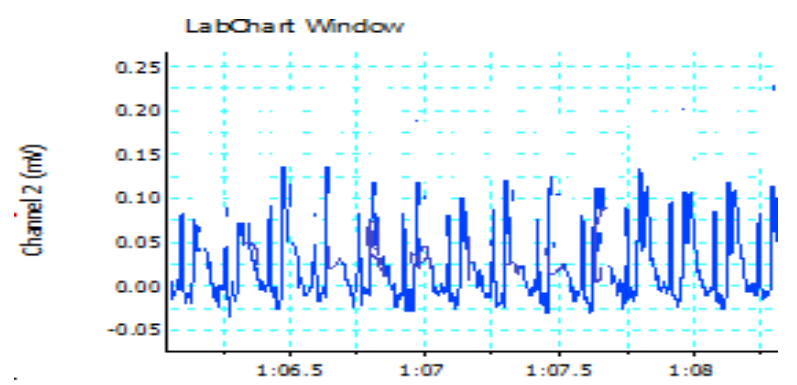

Combination-treated group at the end of reperfusion

Photo (1): Effect of MI/R alone or pretreated with cilostazol (20 mg/kg, p.o.), clopidogrel (30 $\mathrm{mg} / \mathrm{kg}$, p.o.) or their combination on the T-wave voltage in experimentally induced myocardial ischemia/reperfusion (MI/R) in male albino rats.

\section{Effects on the mean arterial blood pressure}

As shown in Fig 2 LCAL decreased significantly $(\mathrm{p} \leq 0.05)$ the MABP as compared to the control normal and sham-operated rats. On the other hand cilostazol or clopidogrel treatment before LCAL produced insignificant $(\mathrm{p} \geq 0.05)$ changes in the $\mathrm{MABP}$ as compared to the MI/R group at the same time of the experiment.

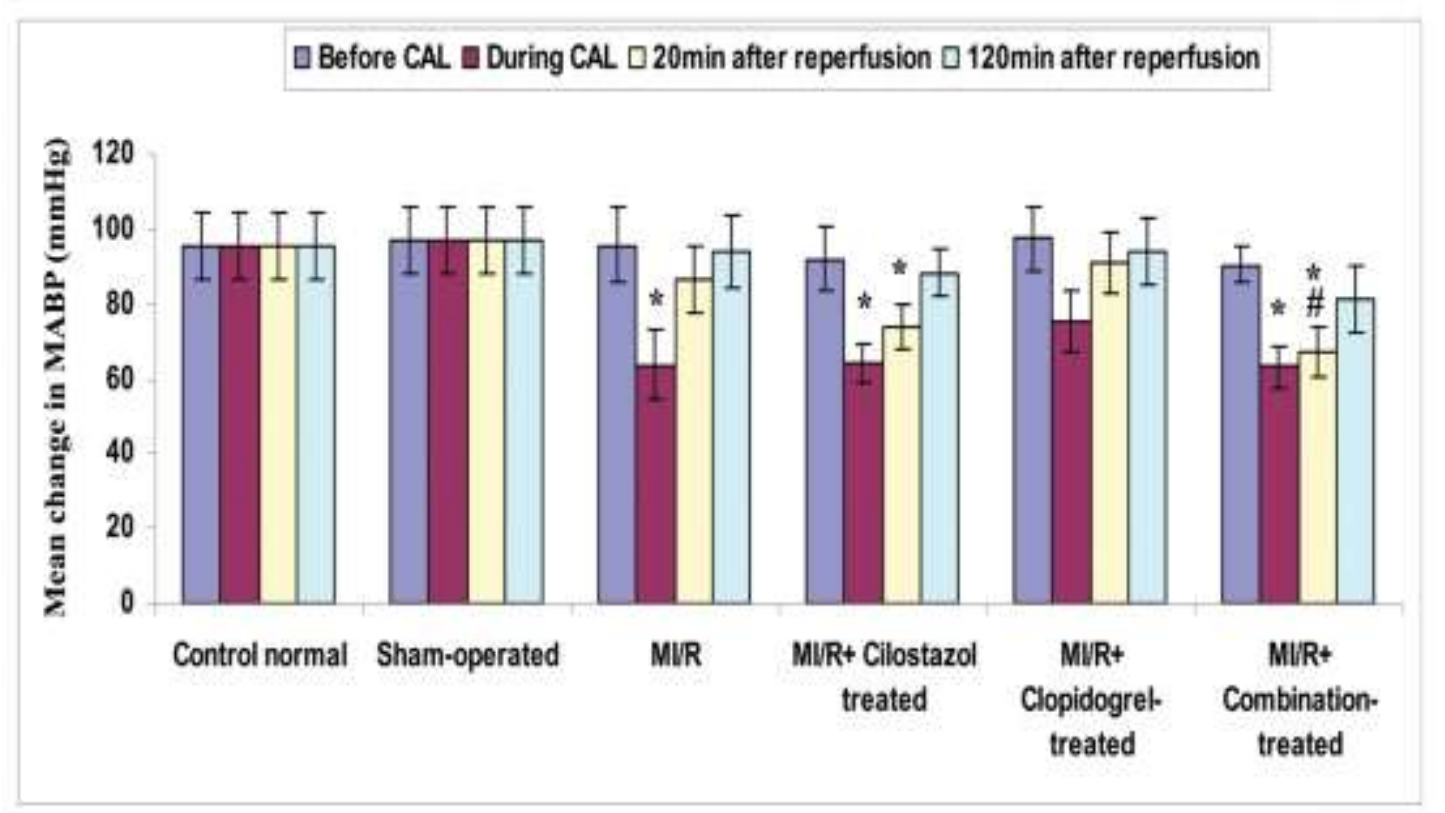

Fig. (2): Effect of pretreatment with cilostazol (20 mg/kg, p.o.), clopidogrel (30 mg/kg, p.o.) or their combination on MABP in experimentally induced myocardial ischemia/reperfusion $(\mathrm{MI} / \mathrm{R})$ in male albino rats.

Data represent the means of eight experiments \pm SEM. 
* Significantly different compared with normal; \# significantly different compared with MI/R using one way ANOVA, followed by LSD test for multiple comparison between groups at $\mathrm{P} \leq 0.05$.

\section{Effects on the heart rate}

As shown in Fig 3 cilostazol treatment for 3 days before the LCAL (20 $\mathrm{mg} / \mathrm{kg} /$ day) significantly $(\mathrm{p} \leq 0.05)$ increased the $\mathrm{HR}$ as compared to the control normal rats.

The results of the present study revealed that LCAL significantly $(\mathrm{p} \leq 0.05)$ increased the HR as compared to the control normal and sham-operated groups. On the other hand, cilostazol significantly $(\mathrm{p} \leq 0.05)$ increased the HR at all times of the experiment. Meanwhile, clopidogrel treatment produced insignificant $(\mathrm{p} \geq 0.05)$ change in the HR as compared to the MI/R group at the same time of the experiment.

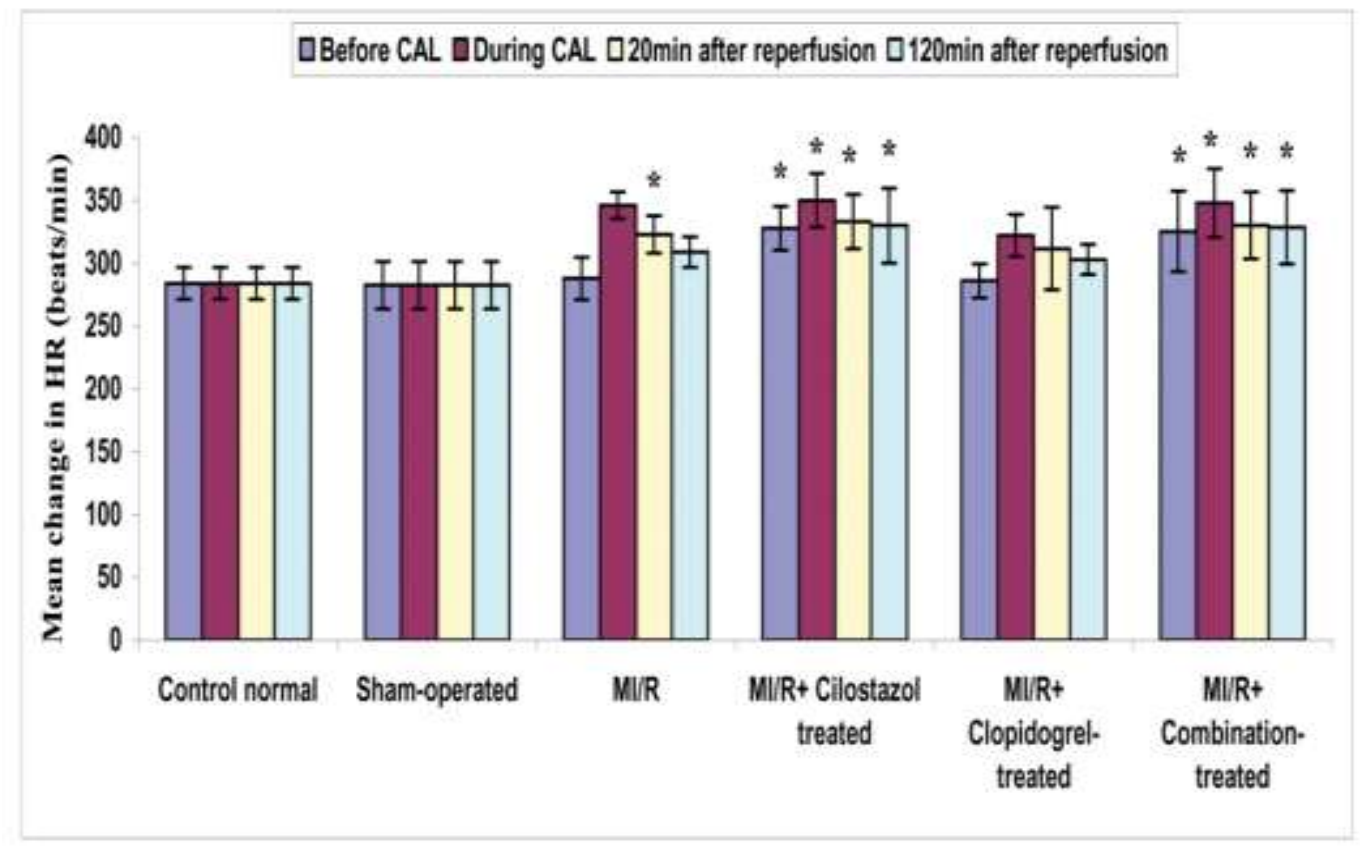

Fig. (3) Effect of pretreatment with cilostazol (20 mg/kg, p.o.), clopidogrel (30 mg/kg, p.o.) or their combination on the heart rate (HR) in experimentally induced myocardial ischemia/reperfusion $(\mathrm{MI} / \mathrm{R})$ in male albino rats.

Data represent the means of eight experiments \pm SEM.

* Significantly different compared with normal using one way ANOVA, followed by LSD test for multiple comparisons between groups at $\mathrm{P} \leq 0.05$.

\section{Effect on myocardial infarct size}

As shown in Fig 4, photo 2 and graph 2, administration of cilostazol (20 mg/kg), clopidogrel $(30 \mathrm{mg} / \mathrm{kg})$ and their combination caused significant $(\mathrm{p} \leq 0.05)$ reduction of 
infarct size by $47 \%, 40 \%$ and $58 \%$, respectively, when compared with that of $\mathrm{MI} / \mathrm{R}$ group (69\% increase as compared to normal rats).

\section{DInfarct size}

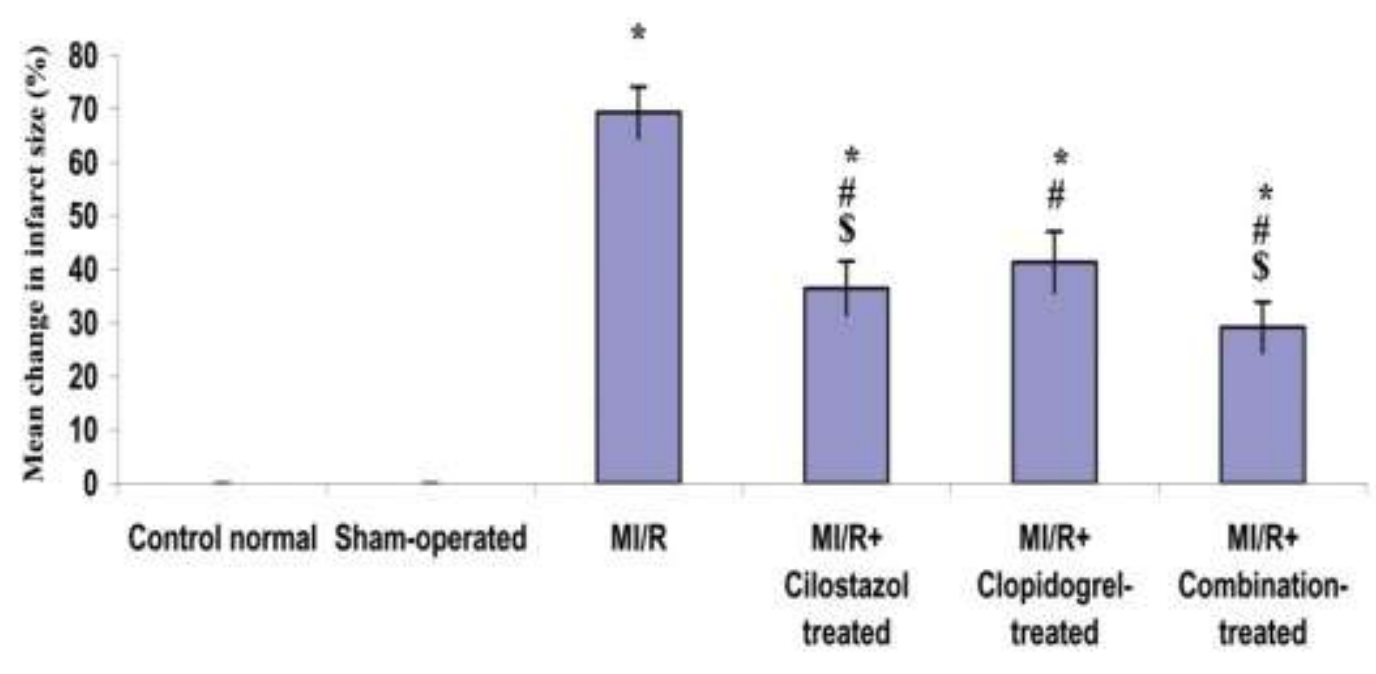

Fig. (4): Effect of pretreatment with cilostazol (20 mg/kg, p.o.), clopidogrel (30 mg/kg, p.o.) or their combination on the myocardial infarct size in experimentally induced myocardial ischemia/reperfusion (MI/R) in male albino rats.

Data represent the means of eight experiments \pm SEM.

* Significantly different compared with normal; \# significantly different compared with MI/R; \$ significantly different compared with clopidogrel using one way ANOVA, followed by LSD test for multiple comparison between groups at $\mathrm{P} \leq 0.05$. 


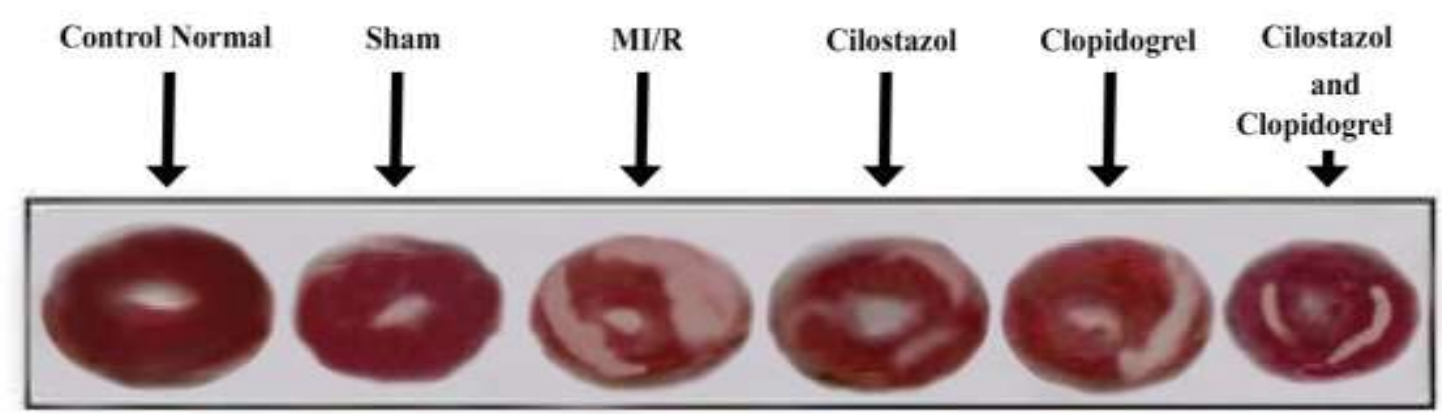

Photo (2): Effect of pretreatment with cilostazol (20 mg/kg, p.o.), clopidogrel (30 $\mathrm{mg} / \mathrm{kg}$, p.o.) or their combination on the infarct size in rat hearts subjected to $30 \mathrm{~min}$ of ischemia, followed by $2 \mathrm{~h}$ of reperfusion. White areas indicate infarcted tissues using triphenyltetrazolium chloride staining.

\section{Effect on plasma cTnI and TNF- $\alpha$, \& heart MDA content and GPx activity}

Myocardial ischemia for $30 \mathrm{~min}$, followed by $2 \mathrm{~h}$ reperfusion increased significantly $(\mathrm{P} \leq 0.05)$ plasma $\mathrm{cTnI}, \mathrm{TNF}-\alpha$ and cardiac MDA content and decreased cardiac GPx activity compared to control normal group. In contrast, treatment with cilostazol (20mg/kg, p.o.), clopidogrel $(30 \mathrm{mg} / \mathrm{kg}$, p.o.) and their combination significantly $(\mathrm{P} \leq 0.05)$ reduced the elevated plasma cTnI, TNF- $\alpha$ and the MDA content and increased the cardiac GPx activity as compared to the MI/R group values (Fig. $5 \& 6)$.

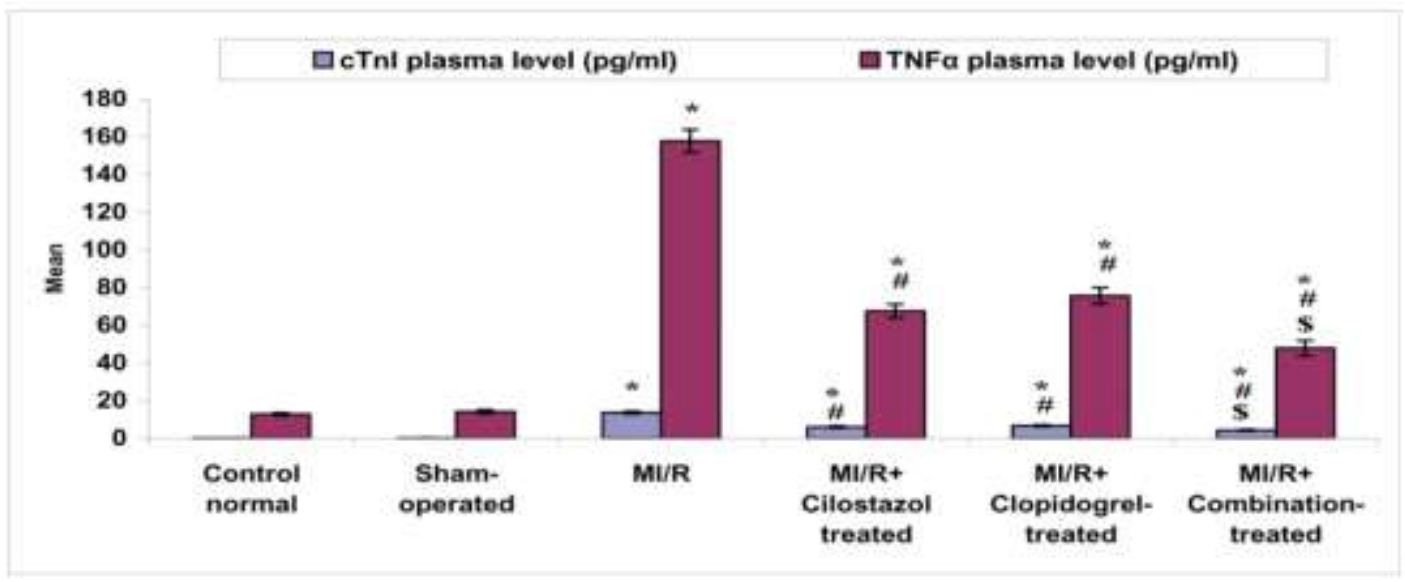

Fig. (5): Effect of pretreatment with cilostazol (20 mg/kg, p.o.), clopidogrel (30 mg/kg, p.o.) or their combination on plasma cTnI and TNF- $\alpha$ level in experimentally induced myocardial ischemia/reperfusion (MI/R) in male albino rats.

Data represent the means of eight experiments \pm SEM.

* Significantly different compared with normal; \# significantly different compared with MI/R; \$ significantly different compared with cilostazol or clopidogrel using one way ANOVA, followed by LSD test for multiple comparison between groups at $\mathrm{P} \leq 0.05$. 


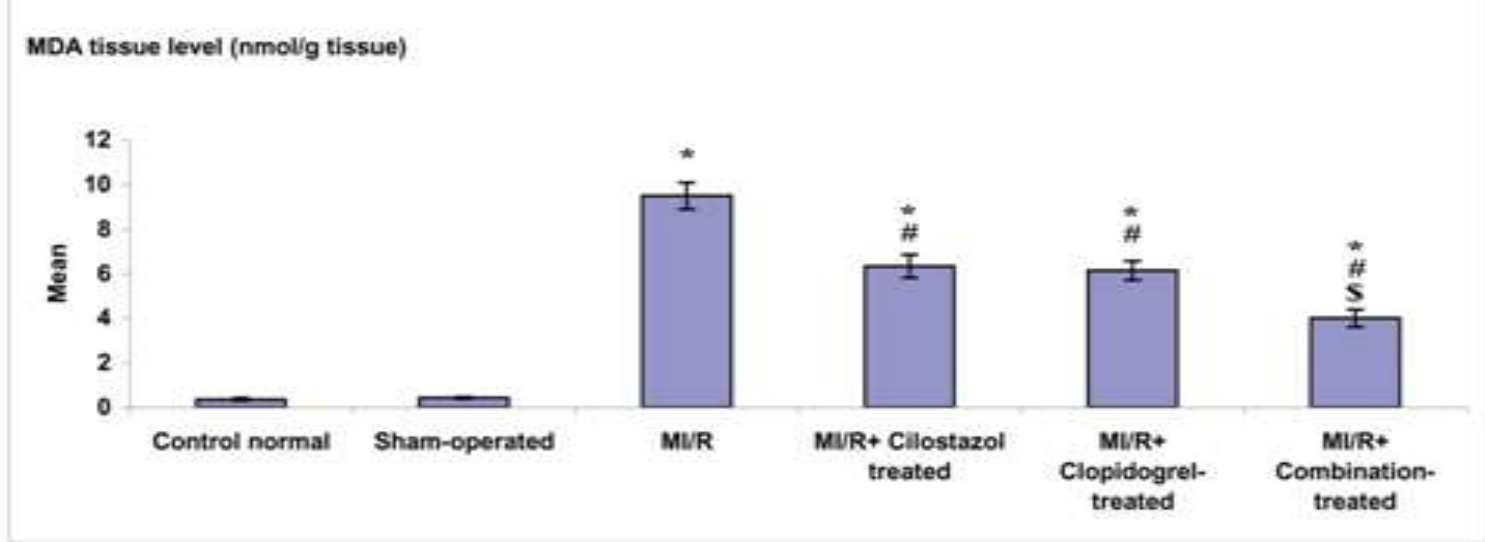

Fig (6A): Effect of $M I / R$ alone or $M I / R$ treated with cilostazol (20 mg/kg, p.o.), clopidogrel $(30 \mathrm{mg} / \mathrm{kg}$, p.o.) or their combination on MDA content in experimentally induced myocardial ischemia/reperfusion (MI/R) in male albino rats.

Data represent the means of eight experiments \pm SEM.

* significantly different compared with normal; \# significantly different compared with MI/R; \$ significantly different compared with cilostazol or clopidogrel using one way ANOVA, followed by LSD test for multiple comparison between groups at $\mathrm{P} \leq 0.05$.

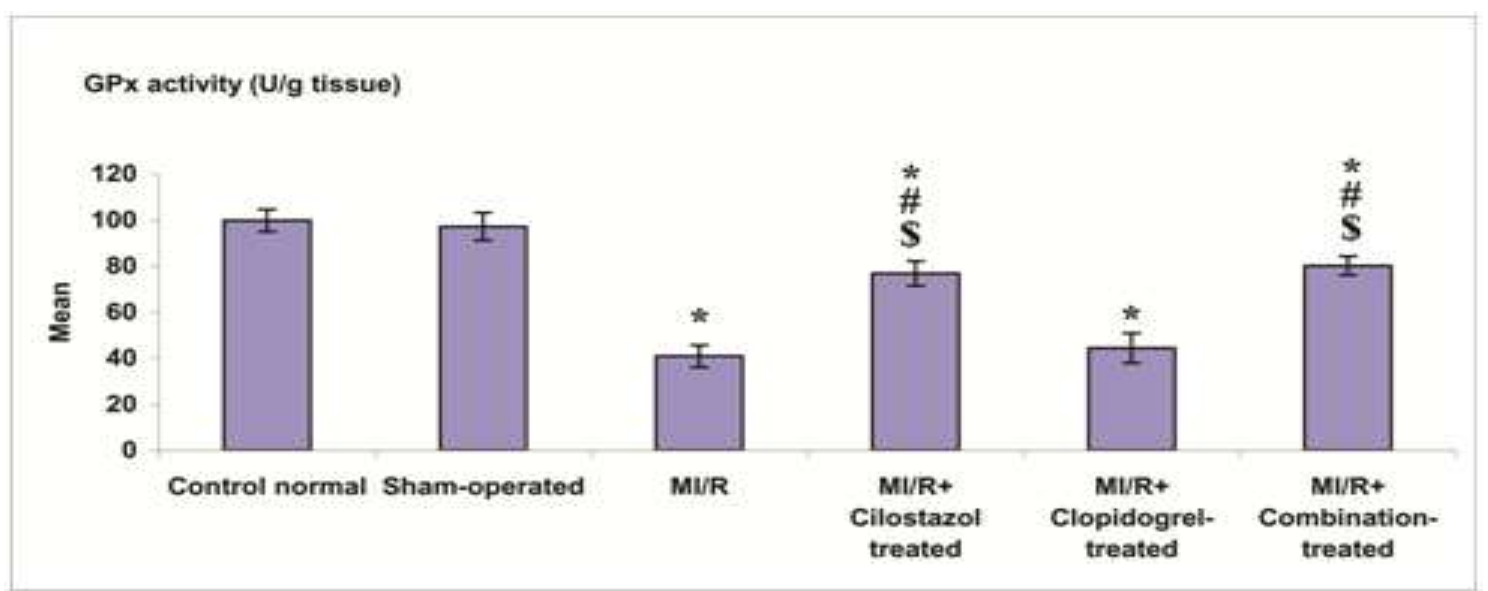

Fig. (6B): Effect of $\mathrm{MI} / \mathrm{R}$ alone or $\mathrm{MI} / \mathrm{R}$ treated with cilostazol (20 $\mathrm{mg} / \mathrm{kg}$, p.o.), clopidogrel $(30 \mathrm{mg} / \mathrm{kg}$, p.o.) or their combination on cardiac GPX activity in experimentally-induced myocardial ischemia/reperfusion (MI/R) in male albino rats.

Data represent the means of eight experiments \pm SEM.

* significantly different compared with normal; \# significantly different compared with MI/R; \$ significantly different compared with clopidogrel using one way ANOVA, followed by LSD test for multiple comparison between groups at $\mathrm{P} \leq 0.05$. 


\section{Effect on plasma lipoproteins levels}

As shown in Fig. 7, treatment with cilostazol (20 mg/kg, p.o.) for 3 days either alone or when combined with clopidogrel significantly $(\mathrm{P} \leq 0.05)$ increased plasma HDL-C and significantly $(\mathrm{P} \leq 0.05)$ decreased plasma LDL-C levels as compared to the control normal group.

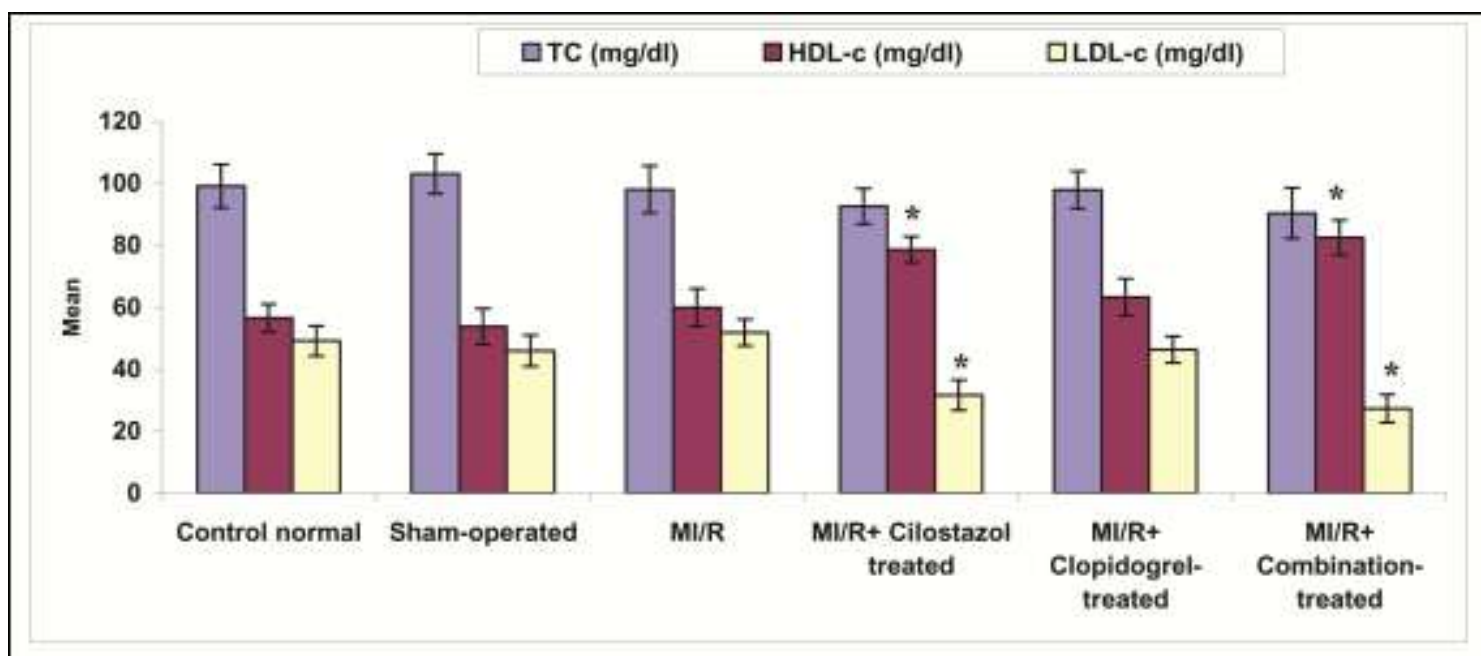

Fig. (7): Effect of pretreatment with cilostazol (20 mg/kg, p.o.), clopidogrel (30 mg/kg, p.o.) or their combination on TC, HDL-C and LDL-C levels ( $\mathrm{mg} / \mathrm{dl})$ in experimentally induced myocardial ischemia/reperfusion (MI/R) in male albino rats.

Data represent the means of eight experiments \pm SEM.

*significantly different compared with normal, sham-operated, MI/R and clopidogreltreated groups using one way ANOVA, followed by LSD test for multiple comparison between group at $\mathrm{P} \leq 0.05$.

\section{Discussion}

Coronary arteries occlusion induces myocardial necrosis leading to myocardial infarction and the primary goal of treatment in those patients is reducing the infarct size. Early reperfusion of an occluded coronary artery is a well-known and effective strategy to reduce ischemia-induced myocardial damage and salvage tissue from inevitable necrosis (Marchant et al., 2012). At the same time, antiplatelet agents are the main pharmacological treatment in those patients, as they decrease the mortality as well as the recurrence of cardiovascular events (Acharji et al., 2013).

However, reperfusion of ischemic myocardium is considered a double-edged sword, as such; restoration of blood flow can provoke further myocardial damage known as ischemia reperfusion (I/R) injury (Jennings et al., 1960; Marchant et al., 2012). The pathogenesis of $\mathrm{I} / \mathrm{R}$-induced myocardial injury involves various factors that lead to further myocardial damage including inflammatory and oxidative stress mediators leading to apoptotic and necrotic myocytes death (Rohilla et al., 2012). 
The results of the present study demonstrated that LCAL produced significant myocardial necrosis in rats evidenced by marked elevation of the T-wave voltage after the $\mathrm{MI} / \mathrm{R}$ in relation to the normal control. Oral pretreatment with cilostazol, clopidogrel or their combination significantly decreased the elevated T-wave amplitude after the MIR in relation to $\mathrm{MI} / \mathrm{R}$ control denoting that both drugs has anti-ischemic effects and combination of both drugs has a synergistic cardioprotective effect.

As regard the HR recordings, the results of the present work revealed that, LCAL, significantly increased the HR in relation to the normal control and then reperfusion significantly decreased it towards the normal level .

Concerning the effects of cilostazol, clopidogrel and the combination of both drugs on the HR after MI/R, the results of the present study revealed that clopidogrel did not produce any significant changes in the HR recordings before and after the $M I / R$ procedure. Meanwhile it was evident in this study that cilostazol either alone or when combined with clopidogrel significantly increased the HR before and after the MI/R.

The accelerating effect of cilostazol on the HR is coinciding with that of Woo et al. (2002) who detected increase the HR about $6 \mathrm{~h}$ after administration of cilostazol in a study that was done to correlate between the peak plasma level of the drug and its cardiovascular effects in healthy individuals. In addition, this increased HR following cilostazol administration was in the same line of that had been reported by Cheng (1999) in that cilostazol is contraindicated in patients with severe heart failure because of this detrimental effect on the heart.

Furthermore, the accelerated HR induced by cilostazol shown in our results is coinciding with the data mentioned by Toyonaga et al. (2000) in that; animal and human studies on cilostazol showed increased HR, myocardial contractile force, ventricular automaticity, and conductivity in the AV node leading to ventricular arrhythmias due to its ability to increase levels of cAMP.

Additionally, the positive chrono-tropic effects of cilostazol were in accordance with Kodama et al. (2003) who reported that cilostazol significantly increased the HR, and recommended usage of the drug safely to selected patients with third degree atrioventricular block over a short term therapy. In addition, these results supported the hypothesis described by Atarashi et al. (1998) and Kishida et al. (2001) who concluded that cilostazol had a beneficial positive chronotropic effect mediated by improvement of conductivity in the atrioventricular node and increase of coronary blood supply caused by dilatation of the vessels. In addition, they recommended the therapeutic utility of cilostazol in patients with bradyarrhythmias.

However, the accelerating effect of cilostazol on the HR was conflicting with those of Bai et al. (2011) who stated that cilostazol pretreatment in a MI/R model in rabbits did not produce significant difference in the HR. Nevertheless, we could explain this conflict in results by the difference in the species and dosages used. In addition, Manickavasagam et al. (2007) showed that 3-days oral pretreatment with cilostazol $(20 \mathrm{mg} / \mathrm{kg} / \mathrm{d})$ in rats before coronary artery occlusion and reperfusion produced insignificant differences in the heart rate. 
In the present study, staining the heart with TTC after MI/R injury showed severe myocardial infarction evidenced by increasing the size of the infarcted tissue. This finding was supported by Zhang et al. (2013) and Chen et al. (2014) who induced acute MI in rats by LCAL followed by reperfusion and reported that in viable myocardium, TTC was converted by dehydrogenase enzymes to formazan, (a red pigment) that stained the tissue dark red and non-viable infarcted myocardium that did not take up the TTC stain remained pale in color.

According to Hallén (2012) the extent of myocardial damage is closely related to prognosis. Therefore, determination of infarct size is the strongest determinant in prognosis of ischemic heart disease. In our study, the infarct size was significantly reduced after cilostazol or clopidogrel pretreatment compared to the MI/R group, indicating a protective effect against ischemia/reperfusion injury. Moreover, the coadministration of cilostazol and clopidogrel produced a more significant decrease in the infarct size compared to that pretreated with clopidogrel alone.

Tang et al. (2013) supported these results in a rat model of $\mathrm{MI} / \mathrm{R}$ and showed that $\mathrm{MI} / \mathrm{R}$ resulted in significant myocardial infarcts and clopidogrel pretreatment, significantly reduced the percentage of the infarcted area.

Additionally, the results of the current study are compatible with those of Manickavasagam et al. (2007) who showed that cilostazol reduced the infarct size in rat hearts stained by TTC after MI/R and they explained this ischemic reduction by increased activation of endothelial nitric oxide synthetase (eNOS) with subsequent stimulation of NO production.

Furthermore, Bai et al. (2011) demonstrated that cilostazol pretreatment significantly reduced the infarct size in a rabbit model of MI/R. They attributed such reduction in infarct size of cilostazol to its ability to increase myocardial levels of adenosine and NO in addition to attenuating superoxide production and opening the mitochondrial $\mathrm{K}_{\mathrm{ATP}}$ channels. They also concluded that cilostazol might be a new strategy for the treatment of coronary heart disease.

The results of the current work were also supported by a study conducted by Ito et al. (2010) to evaluate and compare the effects of anti-platelet agents with different mechanisms of action; cilostazol, and clopidogrel on brain infarction. Moreover, they hypothesized that the cilostazol reducing effect on brain infarct size was due to increasing release of endogenous vasodilator substances from the brain endothelium such as NO and PGI2 leading to enhanced cerebral blood flow in the ischemic region and protection against endothelial dysfunction after ischemic injury.In contrast to our results, Ito et al. (2010) showed that clopidogrel $(3 \mathrm{mg} / \mathrm{kg})$ failed to mitigate infarct size, regardless of their evident inhibitory effects on platelet aggregation. We could explain that conflict with our results by the lower dosage of clopidogrel used in their study and the differences in the animals used as they used hypertensive rats.

Cardiac troponins $\mathrm{T}$ and I are the preferred markers for myocardial injury as they have the highest sensitivities and specificities for the diagnosis of acute myocardial infarction (Christenson and Christenson, 2013). The extent of cTnI elevation strongly correlates 
with infarct size, thus providing indication for the prognosis following an infarction (Ahmet and Yesim, 2015). The results of the present study demonstrated that LCAL produced significant myocardial necrosis in rats evidenced by marked increase in the plasma levels of cTnI, which is in consistence with those results of Doods and Wu (2013) and Zhang et al. (2015) who demonstrated that cTnI is a highly sensitive and specific biomarker of acute myocardial infarction. On the other hand our results revealed that, cilostazol or clopidogrel administration before MI/R significantly reduced the cTnI compared to the MI/R group reflecting their cardioprotective effects. Meanwhile, coadministration of both drugs produced a synergistic decrease in the cTnI more than each drug alone.These results are in accordance with that of Wang et al. (2010) and Mohamed et al. (2014), who reported that the antiplatelet therapy could have an important effect in improving the outcomes in patients with acute MI undergoing primary percutaneous coronary intervention.

The results in the present study showed that ischemia and the ensuing reperfusion injury induced a significant increase in the plasma levels of the proinflammatory cytokine TNF- $\alpha$. These results are in consistent with Li et al. (2011) and Zeng et al. (2012). The increased TNF- $\alpha$ induced by MI/R injury also coincides with those of Frangogiannis et al., (2002) who stated that the reperfusion of ischemic tissue induces an acute inflammatory response leading to necrosis and irreversible vascular endothelial cell injury, which induces complement activation and free radical generation, triggering a cytokine cascade initiated by TNF- $\alpha$ release. This inflammatory reaction is necessary for healing, scar formation in one hand, and can aggravate myocardial injury after ischemia on the other hand.

Similarly, Berthonneche et al. (2004) revealed that TNF- $\alpha$ level increased at $15 \mathrm{~min}$ following ischemia demonstrating that ischemia initiates the myocardial inflammatory response leading to rapid local production of TNF- $\alpha$ and they demonstrated that the proinflammatory cytokine TNF- $\alpha$ modulate cardiovascular function by a variety of mechanisms. Steffens et al. (2009) added that TNF- $\alpha$ depresses myocardial contractility by uncoupling $\beta$-adrenergic signaling, increasing cardiac nitric oxide and peroxynitrite, or altering intracellular calcium homeostasis. TNF- $\alpha$ may also induce structural changes in the failing myocardium, such as cardiomyocyte hypertrophy, interstitial fibrosis, and dilation. Additionally, TNF- $\alpha$ may promote cardiomyocyte apoptosis; it may also activate metalloproteinases and impair the expression of their inhibitors, possibly contributing to cardiac remodeling.

TNF- $\alpha$ promotes cellular inflammatory response by self-amplification and induction of the expression of other proinflammatory cytokines. It is known to have potent ability to attract leukocytes to inflammatory sites, enhancing reactive species generation. Furthermore, it seems to be responsible for regulating products that stimulate inflammation such as NF- $\kappa$ B and COX-2 (Domitrovic et al., 2011).

In our research, both cilostazol and clopidogrel offered additional cardioprotective effects by attenuating the increase in the TNF- $\alpha$ level as compared to the MI/R animals. The most significant decrease in the TNF- $\alpha$ level occurred when the two drugs are coadministered. Therefore, we hypothesized that the protective effects of cilostazol and clopidogrel against myocardial $\mathrm{I} / \mathrm{R}$ injury may be attributed, at least in part, to the suppression of the inflammatory response via the inhibition of pro-inflammatory cytokines. 
Consistent with the aforementioned results Tang et al. (2013) showed that MI/R injury significantly increased the level of serum TNF- $\alpha$ and pretreatment with clopidogrel significantly reduced this elevated TNF- $\alpha$ level. Hadi et al. (2013) also showed that clopidogrel significantly reduced TNF- $\alpha$ levels compared to atherogenic control group in a rabbit model of atherosclerosis.

Furthermore, coinciding with these results are those of Sheu et al. (2012) who showed that cilostazol, clopidogrel or the coadministration of both drugs decreased inflammation in rat critical limb ischemia by decreasing the TNF- $\alpha$ mRNA expressions.

In the present work, myocardial $\mathrm{I} / \mathrm{R}$ injury induced a significant increase in lipid peroxidation markers, reflected by the increased levels of MDA in the MI/R group compared to the control group.Concomitant to the increased MDA formation, a significant decrease in the activities of the antioxidant enzyme, GPx, was observed following myocardial I/R injury, denoting damage to the endogenous antioxidant system induced by $\mathrm{MI} / \mathrm{R}$ injury and confirmed the damage to cardiomyocytes during ischemia/reperfusion. Notably, the finding that GPx activity was decreased by I/R has been reported by Zhang et al. (2011) who reported that reperfusion of ischemic myocardium is accompanied by the development of oxidative stress and the generation of reactive oxygen species (ROS), which play a key role in the oetiopathogenesis of reperfusion injury. The interaction between ROS and cell membrane lipids leads to lipid peroxidation and generation of a cytotoxic product, namely, MDA, which in turn leads to membrane disruption, myocardial cell damage, cardiac dysfunction and irreversible tissue injury. These events occur with concurrent reduction of certain key endogenous self-defense antioxidant compounds such as GPx.

Additionally, Han et al. (2014) had reported that the decline in these endogenous antioxidant enzymes activities causes poor functional recovery of myocardium and cardiac tissue injury after I/R. Therefore, I/R injuries are the outcome of imbalance between the formation of oxidants (ischemic factors) and the availability of endogenous antioxidants (defensive factors) in the heart.

Zhang et al. (2010) confirmed that I/R generates oxygen-derived free radicals, which cause lipid peroxidation, and may result in additional tissue damage, including cardiomyocyte apoptosis. Malondialdehyde is one of the end products of lipid peroxidation, and it is accepted as a marker of ROS-mediated lipid peroxidation of cell membranes in increased systemic oxidative stress.

Dianat et al. (2014) demonstrated that antioxidant enzymes are essential in keeping the physiological functions and play a fundamental role in coping with oxidative stress from endogenous or exogenous sources. Several antioxidant enzymes, such as GPx function synergistically to provide a line of defense against oxidative damage under a variety of stressful conditions, including I/R injury. Therefore, treatment with pharmacological agents with the ability to enhance the activities of antioxidant enzymes, or the enforced overexpression of antioxidant enzymes by using gene transfer approaches represents a potential therapeutic option to attenuate tissue damage induced by $\mathrm{MI} / \mathrm{R}$ injury. The cilostazol reducing effect on infarct size coincided with the results of a study conducted by Lee et al. (2005) in a cerebral ischemia/ reperfusion model in rats. They showed that 
cilostazol decreased the infarct size and that efficacy of cilostazol in this model was largely attributed to mechanisms other than anti-platelet effects and improved cerebral blood flow in the ischemic region. They concluded also that, cilostazol has pleiotropic effects other than anti-platelet and vasodilatory actions. For example, cilostazol suppressed lipid peroxidation in the cerebral spinal fluid after subarachnoid hemorrhage in rat, as shown by decreasing the malondialdehyde contents. Cilostazol also inhibited the production of intracellular ROS and apoptotic death, since reduction of oxidative stress by cilostazol contributed to protection from the brain injury that follows ischemia.

In further support to these reports, the present work showed an increase in GPX activity in cilostazol-treated animals compared to MI/R counterparts. Hence, cilostazol by increasing expression of GPx reverted oxidative damage induced by MI/R and prevented cellular death documented in this investigation. The present results also showed that cilostazol protected the tissues against myocardial I/R-induced injury. This was demonstrated by the effectiveness of cilostazol on arresting lipid peroxidation, indicated by a decrease in MDA levels compared to the MI/R group.

Meanwhile clopidogrel offered a tissue protection against MI/R only by decreasing MDA level compared to the MI/R group without affecting the antioxidant enzyme GPx. Moreover, coadministration of both drugs produced enhanced decrease in the MDA levels and increase in the GPx activity in comparison to each drug alone.

Concerning the effects of cilostazol, clopidogrel or the coadministration of both drugs on lipoproteins levels in the current study during the treatment period and after the MI/R, it was noticed that clopidogrel did not produce any significant changes in the lipoproteins levels compared to that in the control normal rats. Meanwhile, pretreatment with cilostazol either alone or when combined with clopidogrel significantly increased the HDL-C levels and reduced the LDL-C levels as compared to the MI/R group.

Regarding cilostazol effect on lipoproteins Kim et al. (2014) showed that cilostazol alone didn't lead to a significant decrease in the total- and LDL-cholesterol levels in mice fed with hypercholesterolemic diet for weeks. However, when it was combined with a lipidlowering drug probucol, cilostazol significantly decreased TC and LDL-C. In the same line, Elam et al. (1998) and Lee et al. (2001) denoted insignificant effects of cilostazol on LDL$\mathrm{C}$ in rats. However, along with our results it didn't affect the total cholesterol levels in these animals. In the same line of our results are those of Chi et al. (2008) who showed that cilostazol has beneficial effects on plasma lipids producing a $10 \%$ increase in the beneficial HDL-C levels in rats.

In agreement with our study, Mohamed et al. (2014) revealed that the serum levels of TC and triglycerides were significantly elevated in hypercholesterolemic rats with acute MI and clopidogrel pretreatment did not lead to a significant reduction in their levels.Contradictory to our results was a study conducted by Sirinivas et al. (2008) to assess the antiatherosclerotic effect of clopidogrel in rats. They noticed that clopidogrel significantly reduced the TC and LDL-C in a high fat (atherogenic) diet fed rats. This controversy with our results can be attributed to the differences in the diet used in that study as they fed the animals a high fat (atherogenic) diet for weeks. 
In conclusion, cilostazol and clopidogrel combinations are better than each drug alone in decreasing the severity of the MI/R injury by decreasing the ischemic markers and lipid peroxidation parameters, augmenting endogenous antioxidants, and hence, protect myocardium against MI/R-induced oxidative stress injuries. Moreover, cilostazol was proved to be an important therapeutic agent for limiting the severity and functional deficits associated with myocardial I/R injury. Therefore, we recommend the combination of both drugs as a cardioprotective treatment against MI/R injury. Moreover, further experimental and clinical studies are required to confirm our results; and data reported in our study may represent a key for delivery of novel drugs, which participate in planning a new strategy in management of ischemic heart diseases.

\section{REFERENCES}

Acharji S, Lakshmanodoss U, Rudzi-nski W, Stapleton D and Kaluski E (2013): Use of antiplatelet agents in patients with atherosclerotic diseases. Postgrad. Med. 125(5):19-30.

Ahmet Y and Yesim O (2015): An overview of the significance of troponin in acute myocardial infarction. Acta Med. 4: 15-20.

Amsterdam EA, Wenger NK, Brindis, RG, Casey DE, Ganiats TG, Holmes DR, Jaffe AS, Jneid H, Kelly RF, Kontos MC, Levine GN, Liebson PR, Mukherjee D, Peterson ED, Sabatine MS, Smalling RW and Zieman S J (2014): 2014 AHA/ACC Guideline for the management of patients with non-STelevation acute coronary syndromes: executive summary: A report of the American College of Cardiology/ American Heart Association Task Force on Practice Guidelines. J. Am. Coll. Cardiol.; 64(24):2645-2687.

Atarashi H, Endoh Y, Saitoh H, and Kishida H (1998): Chrontropic effects of cilostazol, a new antithro-mbotic agent, in patients with bradyarrhythmias. J. Cardiovasc. Pharmacol. 31 (4):534-539.

Bai Y, Muqier, Murakami H, Sumi S, Yamada Y, Ushikoshi H, Aoyama T, Nishigaki K, Takemura G, Uno B and Minatoguchi S. (2011):Cilostazol protects the heart against ischaemia reperfusion injury in a rabbit model of myocardial infarction: Focus on adenosine, nitric oxide and mitochondrial ATP-sensitive potassium channels. Clin. Exp. Pharmacol. Physiol. J. 38 (10):658-665.

Berthonneche C, Sulpice T, Boucher F, Gouraud L, de Leiris J , O'Connor SE , Herbert JM and Janiak P (2004): New insights into the pathological role of TNF- $\alpha$ in early cardiac dysfunction and subsequent heart failure after infarction in rats. Am.J. Physiol Heart Circ. Physiol. 287 (1): H340-H350.

Birnbaum Y (2014): Ticagrelor, but not clopidogrel, protects the heart and limits myocardial infarct size. 4th International Conference on Clinical \& Experimental Cardiology. J.Clin. Exp. Cardiol. 5:3. 
Cannon CP and Braunwald E (2012): Unstable angina and non-ST elevation myocardial infarction. In Bonow RO, Mann DL, Zipes DP, Libby P. Braunwald's heart disease: A textbook of cardiovascular medicine, chap 56, 9th ed., Saunders publisher, pp. 1178-1209.

Chen TL, Zhu GL, He XL, Wang JA, Wang Y and Qi GA (2014): Short-term pretreatment with atorvastatin attenuates left ventricular dysfunction, reduces infarct size and apoptosis in acute myocardial infarction rats. Int. J.Clin. Exp. Med. 7(12):4799-4808.

Cheng JW (1999): Cilostazol. Heart Dis. 1(3):182-186.

Chi YW, Lavie CJ, Milani RVand Christopher JW (2008): Safety and efficacy of cilostazol in the management of intermittent claudication.Vasc. Health Risk Manag. 4(6): 1197-1203.

Christenson E and Christenson RH (2013): Characteristics of cardiac troponin measurements. Coron. Artery Dis. 24(8):698-704.

DianatM ,Hamzavi GR, Badavi M, and Samarbafzadeh. A (2014): Effects of losartan and vanillic acid co-administration on ischemia-reperfusion-induced oxidative stress in isolated rat heart. Iran Red. Crescent. Med. J. 16(7): e16664.

Domitrovic R, Jakovacb $H$ and Blagojevic G (2011): Hepatoprotective activity of berberine is mediated by inhibition of TNF- $\alpha, \mathrm{COX} 2$ and iNOS expression in CCl4-intoxicated mice. Toxicology 280(1-2):33-43.

Doods H and Wu D (2013): Sabiporide Reduces Ischemia-Induced Arrhythmias and Myocardial Infarction and Attenuates ERK Phosphorylation and iNOS Induction in Rats. Biomed. Res. Int.2013:504320.

Elam MB, Heckman J, Crouse JR, Hunninghake JA, Herd M, Davidson IL, GordonEB andBortey WP (1998): Effect of the novel antiplatelet agent cilostazol on plasma lipoproteins in patients with intermittent claudication. Arterio-scler.Thromb.Vasc. Biol. 18:1942-1947.

Frangogiannis NG, Smith CW and Entman ML (2002): The inflamma-tory response in myocardial infarction. Cardiovasc. Res. 53(1):31-47.

Frantz S, Calvillo L, Tillmanns J Elbing I, Dienisch C, Bischof H, Ertle G, and Bauersachs J (2005): Repetitive postprandial hyperglycemia increases cardiac ischemia/reperfusion injury: prevention by the alpha-glucosidase inhibitor acarbose. FASEB J 19 (6): 591-593.

Gosh MN (1971): Fundamentals of experimental pharmacology. $1^{\text {st }}$ ed., Scientific Book Agency Calcutta, India. 
Hadi NR, Mohammad BI, Ajeena IM, and Sahib HH (2013): Antiatherosclerotic potential of clopidogrel: antioxidant and anti-Inflammatory approaches. Biomed. Res. Int.2013:790263.

Hallén J (2012):Troponin for the estimation of infarct size: what have we learned? Cardiology 121(3): 204-212.

Han J, Wang D, Yu B, Wang Y, Ren H, Zhang B, Wang Y and Zheng Q (2014): Cardioprotection against Ischemia/ Reperfusion by Licochalcone B in Isolated Rat Hearts. Oxid. Med. Cell.Longev.2014: 134862.

Humphreys RA, Haist JV and Chakra-barti S (1999): Orally administered NHE1 inhibitor cariporide reduces acute responses to coronary occlusion and reperfusion. Am. J. Physiol. 276(2): H749-H757.

Ito H, Hashimoto A, Matsumoto Y,Yao H andMiyakoda G (2010):Cilostazol, a phosphodiesterase inhibitor, attenuates photothrombotic focal ischemic brain injury in hypertensive rats. J.Cereb.Blood Flow Metab. 30(2): 343-351.

Jang IS, Park MY, Shin IW, Sohn JT, Lee HK, and Chung YK (2010): Ethyl Pyruvate Has Anti-Inflammatory and Delayed Myocardial Protective Effects after Regional Ischemia/Reperfusion Injury. Yonsei Med. J. 51(6):838-844.

Jennings RB, Sommers HM, Smyth GA, Flack HA and Linn H (1960): Myocardial necrosis induced by temporary occlusion of a coronary artery in the dog. Arch.Pathol. 70:68-78.

Kim IS, Jeong YH and Park Y (2011): Platelet inhibition by adjunctive cilostazol versus high maintenance-dose clopidogrel in patients with acute myocardial infarction according to cytochrome P450 2C19 genotype. J. Am. Coll. Cardiol. 4 (4):381391.

Kim JH, Hong KW, BaeSS,Shin YI, Choi BT and Shin HK (2014): Probucol plus cilostazol attenuate hypercholesterolemia-induced exacerbation in ischemic brain injury via anti-inflammatory effects. Int. J. Mol. Med. 34(3): 687-694.

Kishida M, Watanabe $K$ and Tsuruoka T (2001): Effects of cilos-tazol in patients with bradycardiac atrial fibrillation. J. Cardiol, 37(1):27-33.

Kodama T K,KurataA,Oshima K,Yamamoto K. and Uemura s. (2003): Effect of ciolstazol on the ventricular escape rate and neurohumoral factors in patients with third-degree atrioventricular block. Chest 123(4):1161-1169.

Lee TM, Su SF, Hwang JJ, Tseng CD, Chen MF, Lee YT and Wang SS (2001): Differential lipogenic effects of cilostazol and pentoxifylline in patients with intermittent claudication: potential role for interleukin-6. Atherosclerosis $158: 471-476$. 
Lee JH,Park SY, Lee WS andHong KW (2005): Lack of antiapoptotic effects of antiplatelet drug, aspirin and clopidogrel and antioxidant MCI-186, against focal ischemic brain damage in rats. Neurol. Res.27:483-492.

Li C, Gao Y, Xing Y, Zhu H, Shen J and Tian J (2011):Fucoidan, a sulfated polysaccharide from brown algae, against myocardial ischemia-reperfusion injury in rats via regulating the inflammation response. Food Chem.Toxicol. 49:20902095.

Manickavasagam S, Ye Y, Lin Y, Perez-Polo RJ, Huang MH, Lui CY, Hughes MG, McAdoo DJ, Uretsky BF and Birnbaum Y. (2007): The cardioprotective effect of a statin and cilostazol combination: relationship to Akt and endothelial nitric oxide synthase activation. Cardiovasc.Drugs Ther. 21(5):321-30.

Marchant DJ, Boyd JH, Lin DC, Granville DJ, Garmaroudi FS and McManus BM (2012): Inflammation in myocardial diseases. Circ. Res. 110(1):126-144.

Mohamed AR, El-Hadidy WF and Mannaa HF (2014): Assessment of the prophylactic role of aspirin and/or clopidogrel on experimentally induced acute myocardial infarction in hypercholesterolemia rats. Drugs 14(4): 233-239.

Moran AE, Forouzanfar MH, Roth GA,Mensah GA, Ezzati M, Flaxman A, Christopher JL and Naghavi M (2014): The global burden of ischemic heart disease in 1990 and 2010: the Global Burden of Disease 2010 study. Circulation 129: 1493-1501.

Nachlas MM and Schnitka TK (1963): Macroscopic identification of early myocardial infarcts by alteration in dehydrogenase activity. Am. J.Pathol. 42:379-405.

Naito H K (1984): High-density lipoprotein (HDL) cholesterol. In: Clinical Chemistry: Theory, Analysis and Correlation, Kaplan, A. (Ed.), Mosby Co., Toronto.

Okada M, Matsui H, Ito Y, Fujiwara A and Inano K (1998): Low-density lipoprotein cholesterol can be chemically measured. J. Lab. Clin. Med. 132: 195-201.

Paglia DE and Valentine WN (1967): Studies on the quantitative and qualitative characterization of erythrocyte glutathione peroxidase. J. Lab.Clin. Med. 70(1):158-169.

Rohilla A, Khan MU andKhanam R (2012):cardioprotective role of atorvastatin in hyperhomocys-teinemic rat hearts. Asian J. Pharm.Clin. Res. 5:120-123.

Rondina MT and Weyrich AS (2013): Targeting phosphodiesterases in anti-platelet therapy. Handb.Exp.Pharmacol. 210:225-238.

Sakurai R, Koo BK, Kaneda H, Bonneau HN and Nagai R(2013):Cilostazol added to aspirin and clopidogrel reduces revascularization without increases in major 
adverse events in patients with drug-eluting stents: a meta-analysis of randomized controlled trials. Int. J.Cardiol. 167:2250-8.

Sheu JY, Lin KC, Tsai CY and Chang HW (2012): Combination of cilostazol and clopidogrel attenuates Rat critical limb ischemia. J.Transl. Med. 10:164.

Shinohara Y, Katayama Y, Uchiyama S, Yamaguchi T, Handa S, Matsuoka K, Ohashi Y, Tanahashi N, Yamamoto H, Genka C, Kitagawa Y, Kusuoka H, Nishimaru K, Tsushima M, Koretsune Y, Sawada T and Hamada C (2010): Cilostazol for prevention of secondary stroke (CSPS 2): an aspirin-controlled, double-blind, randomised non-inferiority trial. Lancet Neurol.9:959-968 .

Sirinivas M, Annapurna A and Reddy YN (2008): Anti-atherosclerotic effect of atorvastatin and clopidogrel alone and in combination in rats. Indian J. Exp. Biol. 46: 698-703.

Steffens S, Montecucco F and Mach F (2009): The inflammatory response as a target to reduce myocardial ischaemia and reperfusion injury. Thromb.Haemost. 102:240247.

Tanaka A, Ishii H, Sakakibara M ,Satoshi Okumura S, Jinno Y, Okada K, Suzuki S, Inoue $Y$ andMurohara $T$ (2014): Temporary adjunctive cilostazol vs clopidogrel loading for ST-segment elevation acute myocardial infarction. Am. J. Cardiovasc. Drugs. 14 (2): 131-136.

Tang X, Liu J, Dong W, Li P, Li L, Lin C, Zheng Y, Hou J and Li D (2013): The Cardioprotective Effects of Citric Acid and L-Malic Acid on Myocardial Ischemia/Reperfusion Injury. Evid. Based Complement. Altern. Med.2013: 820695.

Tantry US, Bonello L, Aradi D, Price MJ, Jeong YH, Angiolillo DJ, Stone GW, Curzen N, Geisler T, Berg JT, Kirtane A, Siller-Matula J, Mahla E, Becker RC, Waksman R, Rao SV, Alexopoulos D, Marcucci R, Reny JL and Trenk D (2013): Consensus and update on the definition of on-treatment platelet reactivity to adenosine diphosphate associated with ischemia and bleeding. J. Am. Coll.Cardiol.62:2261.

Toyonaga S,Nakatsu T, Murakami T,Kusachi K and Tominaga Y (2000): Effects of cilostazol on heart rate and its variation in patients with atrial fibrillation associated with bradycardia. J. Cardiovasc. Pharmacol.Ther. 5(3): 183-191.

Utley HC, Bernheim $F$ andHochslein P(1967): Effect of sulfhydryl reagent on peroxidation in microsome. Arch. Biochem. Biophys. 260: 521-531.

Wang CH, Yang J, Shen ZJ, Fang Q, Zhang SY and Fan ZJ (2010): Effect of duration of clopidogrel use on clinical follow-up outcomes in patients with acute myocardial infarction undergoing primary percutaneous coronary intervention. Zhonghua Yi XueZaZhi 90(24):1682-1685. 
Woo SK, Kang WK and Kwon KI (2002): Pharmacokinetic and pharmacodynamic modeling of the antiplatelet and cardiovascular effects of cilostzol in healthy humans. Cli. Pharmacol. Ther.71(4):246-252.

Zeng M, Yan H, Chen Y, Zhao HJ, Lv Y, Liu C, Zhou P and Zhao B (2012): Suppression of NF-кB reduces myocardial no-reflow. PLoS One 7(10):e47306.

Zhang L, Chen X, Su T andLi H (2015): Circulating miR-499 are novel and sensitive biomarker of acute myocardial infarction. J.Thorac. Dis. 7(3):303-308.

Zhang S, Li $\mathbf{H}$ and Yang SJ (2010):Tribulosin protects rat hearts from ischemia/reperfusion injury Acta. Pharmacol. Sin. 31(6): 671-678.

Zhang S, Liu, X, Goldstein S, Li Y, Ge J, He B, Fei X, Wang Z and Ruiz G (2013): Role of the JAK/STAT signaling pathway in the pathogenesis of acute myocardial infarction in rats and its effect on NF-אB expression. Mol. Med. Rep. 7 (1): 93-98.

Zhang Y, Sun Q, He B, Xiao J, Zhinong Wang Z and Sun X (2011): Antiinflammatory effect of hydrogen-rich saline in a rat model of regional myocardial ischemia and reperfusion. Int. J.Cardiol. 148(1):91-95. 
الملخص العربي

التأثير الوقائى لسيلوستازول- مقارنة بكلوبيدوجريل في علاج الجلطة القلبية المحثثة تجريبياً في ذكور الجرذان البيضاء

للسادة الاكاتره

السيد محمد كامل - ليلى احمدمجوب ـ منير هاسماعيل خطابـ دعاء محمدعبداله احمد

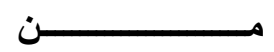

قسم الفارماكولوجيا الاكلينيكية ـ كلية الطب البشري - جامعة الزقازيق

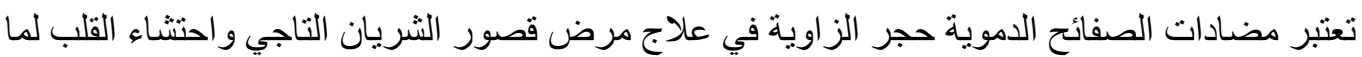

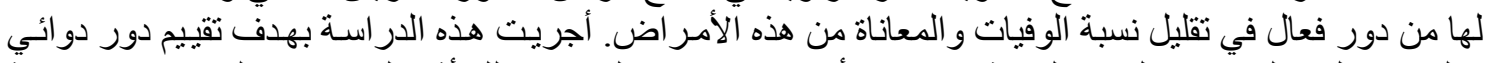

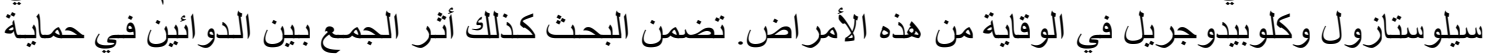

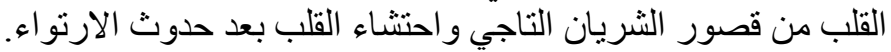

و استخدم في هذا البحث عدد 97 جرذا أبيضـاتم تقسيمها إلى 7 مجموعات متسـاوية كل مجموعـة تحتوي على

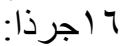

المجمو عة الأولى (ضابطة سلبية): تم إعطاؤها مذيبات الأدوية.

المجمو عةالثانبة (ضابطة|إيجابية): حيث تم عمل جر احة لها دون ربط الثريان التاجي ونم إعطاؤها مذيبات الأدوية.

المجمو عة الثالثة: وقد تم فيها ربط الثريان التاجي الأيسر لمدة • ب دقيقة ثم فلك الربط لحدوث ارنو اء لمدة ساعتين. المجمو عة الر ابعة: حيث أعطيت الجرذان دواء سيلوستازول ـ مجم/كجم. المجمو عة الخامسة: حيث أعطيت الجرذان دواءكلوبيدوجريل • آمجم/كجم.

المجمو عة السادسة: وفيها تم إعطاء الدو ائين معا بنفس الجر عات السابقة.

وقد أعطيت الأدوية فى المجمو عات الر ابعة و الخامسة و السادسة للجرذان عن طريق الفم باستخدام الأنبوبة المعدية

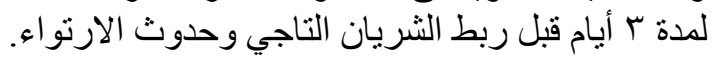

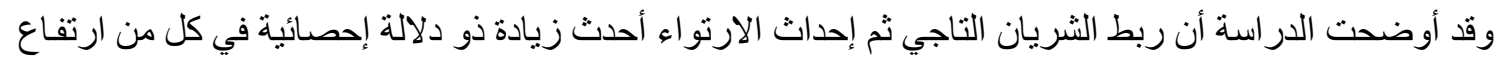

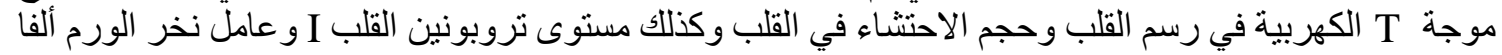

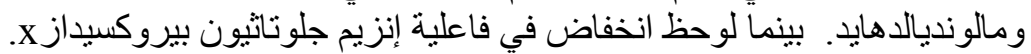

كما بينت الدر اسة أن إعطاء دو ائي سيلوستاز و كلوبيدوجريل منفردين أو معا قد أحدث انخفاضـا ذو دلالة إحصـائية

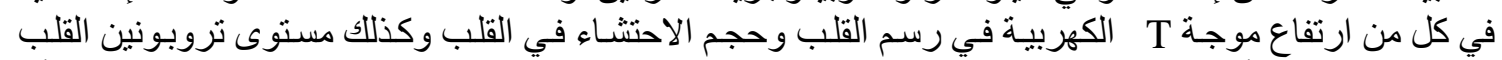

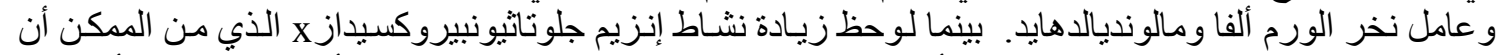

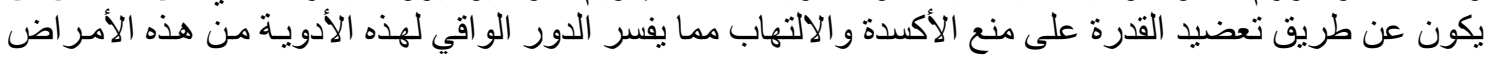
الخطبرة السالف ذكر ها.

الخلاصة: تبين من هذه الدر اسة أن دو ائي سيلوستازو كلو بيدوجريل لهما تأثثر و اقي في حمايـة القلب من الاحتشـاء

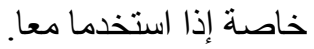

